ARTICLE

DOI: $10.1038 / \mathrm{s} 41467-018-07259-\mathrm{x}$

\title{
Design and 22-step synthesis of highly potent D-ring modified and linker-equipped analogs of spongistatin 1
}

Linda M. Suen ${ }^{1}$, Makeda A. Tekle-Smith', Kevin S. Williamson', Joshua R. Infantine ${ }^{1}$, Samuel K. Reznik , Paul S. Tanis ${ }^{1}$, Tyler D. Casselman ${ }^{1}$, Dan L. Sackett ${ }^{2} \&$ James L. Leighton (1) ${ }^{1}$

Spongistatin 1 is among the most potent anti-proliferative agents ever discovered rendering it an attractive candidate for development as a payload for antibody-drug conjugates and other targeted delivery approaches. Unfortunately, it is unavailable from natural sources and its size and complex stereostructure render chemical synthesis highly time- and resource-intensive. As a result, the design and synthesis of more acid-stable and linker functional groupequipped analogs that retain the low picomolar potency of the parent natural product requires more efficient and step-economical synthetic access. Using uniquely enabling direct complex fragment coupling crotyl- and alkallylsilylation reactions, we report a 22-step synthesis of a rationally designed D-ring modified analog of spongistatin 1 that is characterized by $\mathrm{Gl}_{50}$ values in the low picomolar range, and a proof-of-concept result that the $\mathrm{C}$ (15) acetate may be replaced with linker functional group-bearing esters with only minimal reductions in potency.

\footnotetext{
${ }^{1}$ Department of Chemistry, Columbia University, New York, NY 10027, USA. ${ }^{2}$ Eunice Kennedy Shriver National Institute of Child Health and Human Development, National Institutes of Health, Bethesda, MD 20892, USA. Correspondence and requests for materials should be addressed to

D.L.S. (email: sackettd@mail.nih.gov) or to J.L.L. (email: jll43@columbia.edu)
} 
A mong the large group of natural products known to express their anti-cancer activity by disrupting microtubule dynamics, spongistatin 1 (refs. ${ }^{1-3}$ ) is particularly notable for its extraordinary potency, with an average $\mathrm{GI}_{50}$ value against the NCI panel of 60 human cancer cell lines of $0.12 \mathrm{nM}^{1,4}$. While the clinical utility of this class of compounds is well established, such ultra-potency is often associated with doselimiting toxicities that render them unsuitable for use as standalone chemotherapeutics. Conversely, antibody-drug conjugates (ADCs) target tumor-specific antigens, thereby selectively delivering their cytotoxic payload to the cancer cells and effectively increasing its therapeutic index and minimizing off-target toxicities $^{5-8}$, and because so little drug material is delivered to the cancer cells, it is not only possible but advantageous to employ ultra-potent cytotoxins that might otherwise be too toxic for use as cancer drugs as ADC payloads. Thus, spongistatin 1, which has been shown to exhibit significant in vivo antitumor activity in an orthotopic pancreatic cancer mouse model ${ }^{9}$ and in a melanoma xenograft model $^{10}$, is an attractive candidate for development and evaluation as the drug component of ADCs and other selective cancer cell-targeting conjugates.

The development of a natural product such as spongistatin 1 as a payload for selective cancer cell-targeting conjugates entails the installation of a linker functional group that can be used in efficient, mild, and selective conjugation reactions in a region of the molecule that is not critical for activity such that neither the installation of the linker functional group nor its chemical modification in conjugation reactions result in any significant loss of potency. Additionally, since conjugate payloads must survive prolonged exposure to the low $\mathrm{pH}$ environments of the endosome and lysozome, any acidsensitive groups are likely to be major pharmacological liabilities and must be chemically modified, again in a way that results in no significant loss of potency. This kind of precision modification of natural products ${ }^{11-15}$ to develop them as medicinal agents with enhanced pharmacological properties can be addressed only by total chemical synthesis, and though several ground breaking syntheses of spongistatin 1 and 2 have been reported ${ }^{16-35}$, spongistatin's size and structural and stereochemical complexity necessitate unusually long synthetic sequences that could render such ADC payload development efforts prohibitively laborious and time- and resourceintensive. We therefore set out to devise new strategies and methods that would result in synthetic access to the spongistatins with greatly increased efficiency and step economy, and then to leverage that synthetic efficiency to address the medicinal chemical development of spongistatin 1 as an ADC payload. Here, we report the development of direct complex fragment coupling crotylation and alkallylation reactions, their application to the development of an efficient and step-economical synthesis of the spongistatins, and the use of that synthesis in the design and validation of analogs that incorporate a pharmacologically innocent linker functional group and a redesigned acid-stable CD spiroketal that is both easier to synthesize efficiently and equipotent with the natural product.

\section{Results}

Analog design. Ideally, the identification of a suitable site for the installation of a linker functional group as well as the structural redesign of any acid-sensitive groups with no loss of potency would be guided by structural biological information regarding the interaction of spongistatin 1 with its receptor, but no such information is available. We thus turned to Smith's report that a "diminutive congener" (2) in which the entire C(12)-C(28) region was replaced with a simple linear alkanoate strap retained some significant potency (Fig. 1a) ${ }^{36}$. This suggested to us that the deleted portion of the molecule primarily plays an indirect scaffolding role to favor the biologically active conformation and reduce the entropic cost of binding, and in turn that relatively minor structural modifications may be made in this region with no significant loss of potency. That the CD spiroketal-whose primary role according to this hypothesis is to properly orient the $\mathbf{R}$ and $\mathbf{R}^{\prime}$ groups - is located in this part of the molecule was of particular interest because it occurs in its thermodynamically less stable singly anomeric form and is susceptible to acid-catalyzed isomerization to the thermodynamically more stable doubly anomeric form with an attendant major change in the relative orientation of the $\mathbf{R}$ and $\mathbf{R}^{\prime}$ groups (Fig. 1b). Indeed, all attempts to synthesize it directly by way of an acid-catalyzed spiroketalization reaction of dihydroxy ketones such as $\mathbf{3}$ lead to the doubly anomeric form as the major product necessitating an inefficient and laborious separation/equilibration/separation sequence (Fig. 1b). We hypothesized that a redesigned $\mathrm{CD}^{*}$ spiroketal in which the D-ring oxygen atom has been relocated to the anomeric position and the $\mathrm{C}(25)$ hydroxyl group has been deleted would be (1) readily accessible by efficient and selective spiroketalization of dihydroxyketone 4 ; (2) immune to acidcatalyzed isomerization as it is in its thermodynamically most stable doubly anomeric form; and (3) isostructural with the natural CD spiroketal in terms of the relative orientation of the $\mathbf{R}$ and $\mathbf{R}^{\prime}$ groups, resulting in no significant reduction in potency. In seeking to identify a group that may be amenable to modification to incorporate a linker functional group with no deleterious impact on potency, we noted that the $\mathrm{C}(15)$-OAc group is also located within the deleted region (Fig. 1c). Our focus on this group as a pharmacologically innocent linker group installation site was further supported by the fact that spongistatins 4 and 6 , which differ from spongistatins 1 and 2 only in having a $\mathrm{C}(15)$ $\mathrm{OH}$ group, are equipotent with spongistatins 1 and 2, respectively, while spongistatin 9 , in which the $\mathrm{C}(15)$-oxygen is cyclized onto the $\mathrm{C}(13)$ alkene to form a tetrahydrofuran ring is also equipotent with spongistatin 1 (ref. ${ }^{34}$ ). In stark contrast, the $\mathrm{C}$ (5)-OAc appears to be important for activity in that spongistatin 3 with a free alcohol at C(5) is about an order of magnitude less potent than spongistatin 1 . Together, these data suggest that the $C$ (15)-acetate is not critical for activity, and our aims thus evolved as (1) the development of more step-economical methods and strategies for the synthesis of the spongistatins; (2) synthesis and evaluation of the D-ring-redesigned analog $5 \mathbf{a}(\mathrm{R}=\mathrm{Me})$; and (3) synthesis and evaluation of azide-equipped ester analogs $\mathbf{5}$ $\left(\mathrm{R}=\right.$ linker- $\left.\mathrm{N}_{3}\right)$.

Retrosynthetic analysis. Retrosynthetic disconnection by way of macrolactonization and Wittig reactions ${ }^{19}$ leads to two major fragments of approximately equal complexity, the $\mathrm{ABCD}^{*}$ aldehyde 6, and the EF phosphonium salt 7 (Fig. 2). Within both of these fragments may be found homoallylic alcohols (highlighted in magenta) that could in principle be the products of a syncrotylation reaction of crotylmetal(loid) $\mathbf{8}$ with aldehyde $\mathbf{9 a}$ or $\mathbf{9 b}$, and an alkallylation reaction of allylmetal(loid) $\mathbf{1 0}$ with aldehyde 11, respectively. While we saw in these hypothetical transformations great potential to streamline the synthesis, such direct (i.e. generation and use, without isolation, of the active crotyl-/ allylmetal species) and highly stereocontrolled complex fragment coupling reactions wherein the crotyl or allyl donor is stereochemically and functionally complex were unknown. The critical methodological challenge was thus the generation of versions of $\mathbf{8}$ and $\mathbf{1 0}$ possessed of the necessary reactivity to couple efficiently and highly stereoselectively with aldehydes $\mathbf{9}$ and $\mathbf{1 1}$ from simple and readily available precursors and in a way that does not require their isolation. We were optimistic that our diamine- and diaminophenol-activated crotyl- and allylsilanes ${ }^{37,38}$ would, uniquely, be well-suited for the proposed reactions due both to 
a

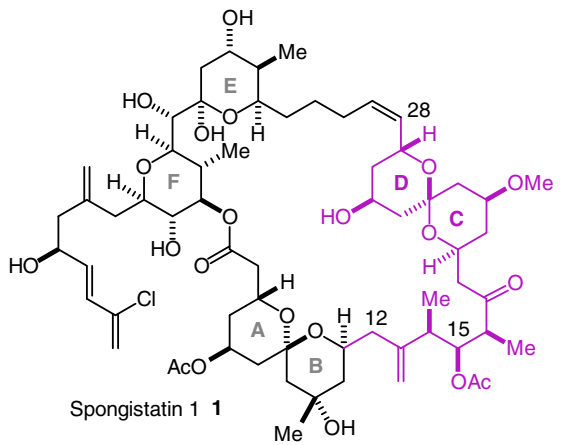

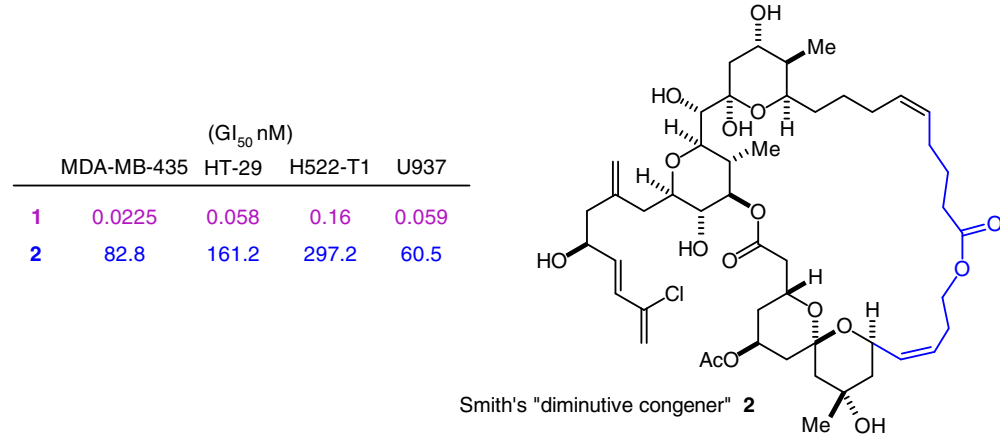<smiles>[H][R]1([H])CC(O)C[C@]2(CC(O)CC([2H])O2)O1</smiles>



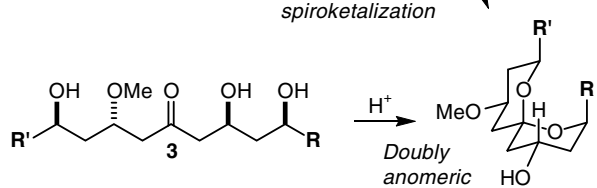

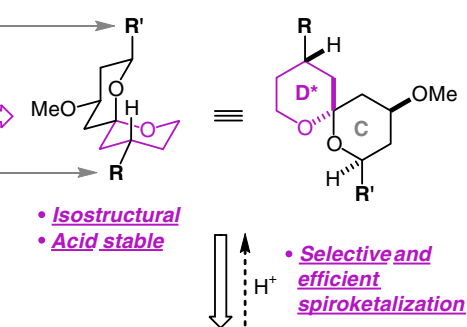



Fig. 1 Spongistatin 1 is an extraordinarily potent anti-mitotic agent whose development is hindered by synthetic inaccessibility. a Smith's simplified analog 2 retains some significant potency suggesting that the $C(12)-C(18)$ fragment and the $C D$ spiroketal are not in contact with the receptor in the bound conformation, and that their role is to serve as scaffolding to lock the compound in its active conformation. $\mathbf{b}$ Relocation of the D-ring oxygen to the anomeric position and deletion of the $\mathrm{C}(25)$ alcohol is proposed to lead to an analog that is isostructural and therefore equipotent with the natural product, stable in the low pH endosomal and lysozomal environments, and significantly easier to synthesize efficiently by spiroketalization of dihydroxyketone $\mathbf{4}$. $\mathbf{c}$ The study aims are the development of efficient synthetic access to the spongistatins, synthesis and evaluation of the $D$-ring modified analog $\mathbf{5 a}$ ( $R=\mathbf{M e}$ ), and validation of the $\mathrm{C}(15)$ acyloxy group as a site for linker functional group incorporation without a significant loss of potency

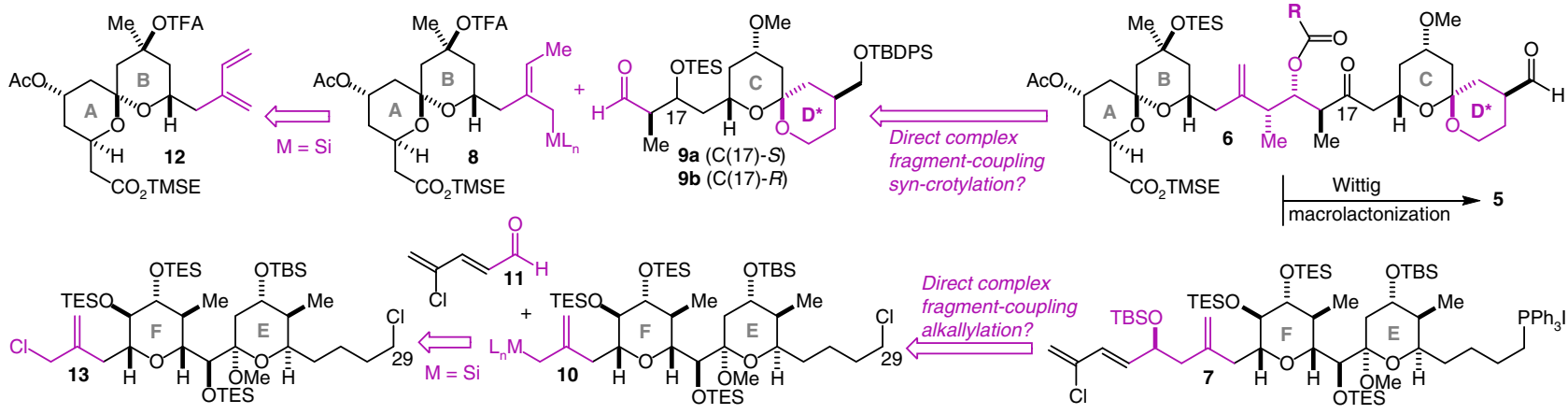

Fig. 2 Retrosynthetic analysis. The target molecules may be split into the $A B C D^{\star}(\mathbf{6})$ and $E F(\mathbf{7})$ fragments, which may be coupled with a Wittig reaction, followed by macrolactonization to complete the synthesis. A direct complex fragment coupling syn-crotylation reaction of $\mathbf{8}$ with $C D^{*}$ spiroketal aldehyde $\mathbf{9 a}$ or $\mathbf{9 b}$ was envisioned as the key step in the synthesis of the $A B C D^{\star}$ fragment, while a direct complex fragment coupling alkallylation reaction of $\mathbf{1 0}$ with aldehyde $\mathbf{1 1}$ was envisioned as a critical step in the synthesis of the EF fragment. Crotyl- and allylsilanes $\mathbf{8}$ and $\mathbf{1 0}(\mathrm{M}=\mathrm{Si}$ ) were envisioned to arise from diene $\mathbf{1 2}$ and allylchloride 13, greatly simplifying the synthesis. TFA trifluoroacetate, TMSE 2-trimethylsilylethyl, TES triethylsilyl, TBDPS tertbutyldiphenylsilyl, TBS tert-butyldimethylsilyl

their reliably excellent reactivity and broad generality and to the fact that the requisite crotyl- and allylsilanes 8 and $\mathbf{1 0}(\mathrm{M}=\mathrm{Si})$ appeared accessible from the simple precursors diene $\mathbf{1 2}$ (ref. ${ }^{39}$ ) and allylchloride 13 by way of mild, functional group-tolerant, and chemoselective transition metal-catalyzed hydrosilylation and allylic substitution reactions, respectively.

Synthesis of the $\mathrm{ABCD}^{\star}$ fragment. Not knowing at the outset which of the $C(17)$ diastereomeric aldehydes $9 a$ and $\mathbf{9 b}$ would perform best in the critical fragment coupling crotylation reaction, we developed a flexible and efficient route to both (Supplementary Figs. 1-3). The final 11-step route to $\mathbf{9 b}(\mathrm{C}(17)$ $R)$ is representative and entailed a 1,3-anti diastereoelective Mukaiyama aldol reaction ${ }^{40}$ of aldehyde 14 with silyl enol ether $\mathbf{1 5}$ to give $\mathbf{1 6}$ in $70 \%$ yield (Fig. 3a). Methyl ether formation then delivered 17 in $83 \%$ yield, setting the stage for the vital spiroketalization reaction to form the redesigned $\mathrm{CD}^{\star}$ spiroketal. Treatment of $\mathbf{1 7}$ with pyridinium $p$-toluenesulfonate in $\mathrm{MeOH}$ did indeed effect a robust and highly diastereoselective spiroketalization reaction to form the desired doubly anomeric 

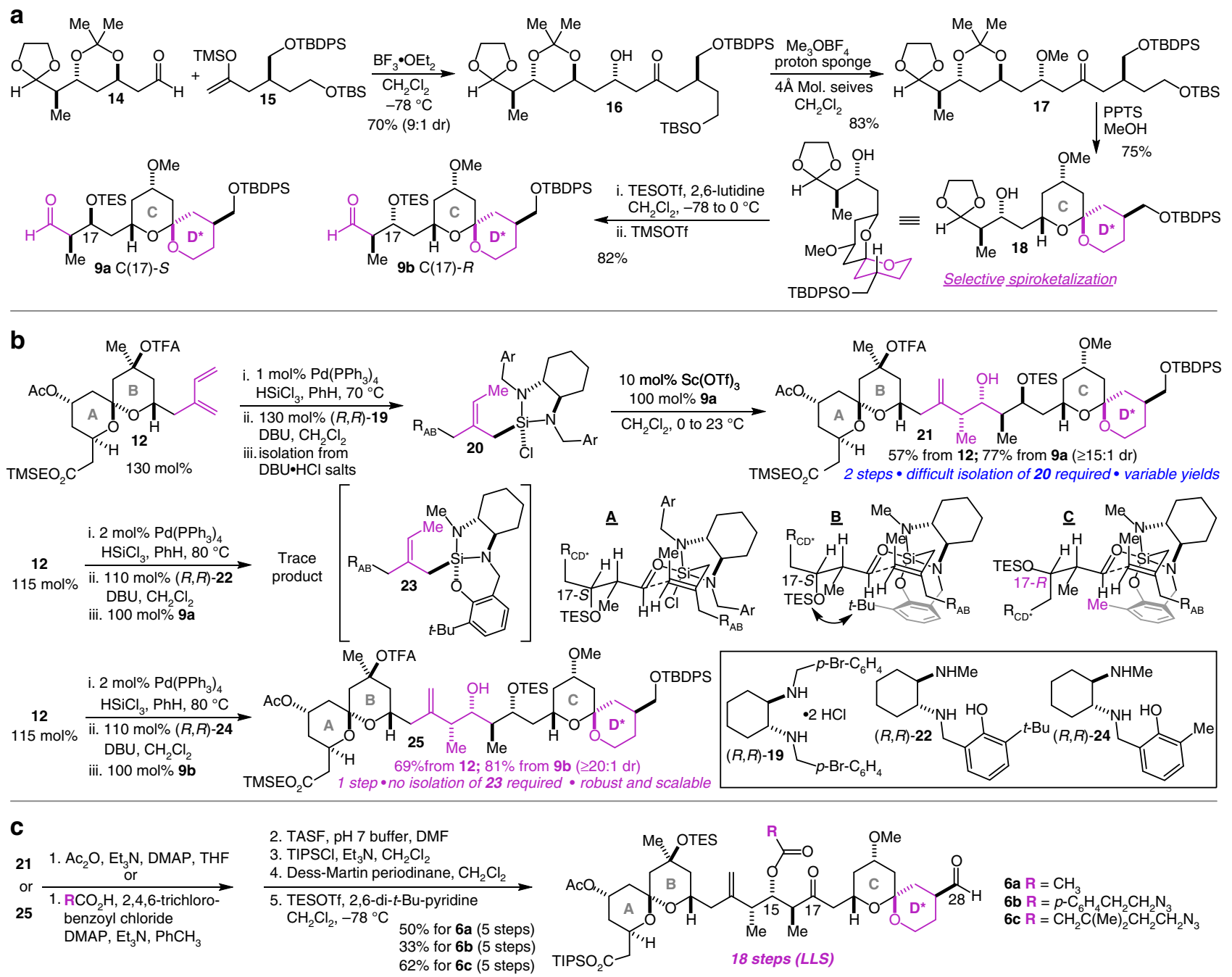

6a $\mathrm{R}=\mathrm{CH}_{3}$

6b $\mathrm{R}=p-\mathrm{C}_{6} \mathrm{H}_{4} \mathrm{CH}_{2} \mathrm{CH}_{2} \mathrm{~N}$ $62 \%$ for 6 c (5 steps)

Fig. 3 An 18-step synthesis of the fully elaborated $A B C D^{\star}$ fragment of the spongistatins. $\mathbf{a}$ The synthesis of the redesigned $C D^{\star}$ spiroketals $\mathbf{9 a}$ and $\mathbf{9} \mathbf{b}$ entails as key steps a Mukaiyama aldol reaction and a diastereoselective spiroketalization reaction. $\mathbf{b}$ The direct complex fragment coupling syn-crotylation reaction to join $A B$ spiroketal diene $\mathbf{1 2}$ with $C D^{\star}$ spiroketal aldehyde $\mathbf{9 b}$ to produce $\mathbf{2 5}$ in a single step is robust and scalable and is the crucial innovation in the development of a highly step-economical and efficient synthesis of the $A B C D^{\star}$ fragment of the spongistatins. c Five straightforward steps convert $\mathbf{2 1}$ and $\mathbf{2 5}$ into the completed $A B C D^{\star}$ fragment $\mathbf{6 a}$ and linker-equipped analogs $\mathbf{6 b}$ and $\mathbf{6 c}$. DBU1,8-diazabicyclo[5.4.0]-undec-7-ene, DMAP4dimethylaminopyridine, TASF tris(dimethylamino)sulfonium difluorotrimethylsilicate

spiroketal $\mathbf{1 8}$ in $75 \%$ yield. Treatment of $\mathbf{1 8}$ with triethylsilyl triflate (TESOTf) and then trimethylsilyl triflate (TMSOTf) resulted in sequential alcohol protection and acetal deprotection to give $\mathrm{CD}^{*}$ spiroketal aldehyde $\mathbf{9 b}$ in $82 \%$ yield. An earlier version of this route was used to access $9 \mathbf{a}(\mathrm{C}(17)-S)$, and it was with this aldehyde that our investigation of the complex fragment coupling crotylation reaction began based on a model study which suggested that this stereochemical permutation would represent a matched case in the fragment coupling crotylation reaction ${ }^{37}$. Indeed, palladium-catalyzed hydrosilylation of diene 12 (ref. ${ }^{41}$ ) followed by complexation with diamine $(R, R)-19$ produced crotylsilane 20, which was employed in our firstgeneration $\mathrm{Sc}(\mathrm{OTf})_{3}$-catalyzed crotylation protocol ${ }^{37}$ with 9a leading to the isolation of $\mathbf{2 1}$ with high $(\geq 15: 1)$ diastereoselectivity (Fig. 3b). While we were gratified by this proof-of-concept result, the requirement for isolation of the intermediate crotylsilane $\mathbf{2 0}$ (necessary because the $\mathrm{DBU} \cdot \mathrm{HCl}$ salts poison the $\mathrm{Sc}(\mathrm{OTf})_{3}$ catalyst) was deemed highly problematic in that crotylsilanes such as 20 are prone to degradation when exposed to moisture both rendering the isolation technically difficult and risky and leading to significant variability in the yield of the reaction. Motivated to address these limitations, we recently developed a secondgeneration diaminophenol ligand (22) that induces reactivity in its derived crotylsilanes equivalent to the diamine $19 / \mathrm{Sc}(\mathrm{OTf})_{3}$ combination, but without requiring the $\mathrm{Sc}(\mathrm{OTf})_{3}$ catalysis $^{38}$, which allows its use in a direct one-pot protocol without isolation of the crotylsilane prior to reaction with the aldehyde. When this protocol was employed to generate and react (without isolation) crotylsilane $\mathbf{2 3}$ with $\mathbf{9 a}$, however, we were surprised to find that the reaction produced, at best, trace amounts of the desired product. Based on a computational model for the first-generation crotylsilylation reaction ${ }^{42}$ and on Evans' comprehensive model for merged 1,2- and 1,3-stereoinduction in related aldol reactions $^{43}$, we constructed transition state model $\mathbf{A}$ for the successful reaction of first-generation crotylsilane $\mathbf{2 0}$, and then applied it to the reaction of crotylsilane $\mathbf{2 3}$ to construct transition state model B. This exercise revealed that the tethering of the phenol to the silane with diaminophenol ligand $\mathbf{2 2}$, which induces the greater 
reactivity in the silane, also has the unintended consequence of generating a prohibitive steric interaction between the $t$-Bu group on the phenol ring and the $\beta$-OTES group on the aldehyde. We hypothesized that we could alleviate this interaction by employing diaminophenol $(R, R)$-24 with a methyl group in place of the $t$ - $\mathrm{Bu}$ group and by employing $\mathrm{CD}^{*}$ aldehyde $\mathbf{9 b}(\mathrm{C}(17)-R)$, to result in a reaction that would proceed smoothly by way of transition structure $\mathbf{C}$. Gratifyingly, this proved to be the case with the crotylsilane formed from diene $\mathbf{1 2}$ and $(R, R)$-24 reacting with aldehyde $\mathbf{9 b}$ to give the desired product $\mathbf{2 5}$ as a single diastereomer in $69 \%$ yield from diene $\mathbf{1 2}$ and in $81 \%$ yield from aldehyde $\mathbf{9 b}$. Crucially, because no isolation of the crotylsilane is necessary, the reaction is robust, reproducible, and scalable, and in one case was used to synthesize $1.27 \mathrm{~g}$ of $\mathbf{2 5}$ in a single run. Completion of the $\mathrm{ABCD}^{*}$ fragment synthesis comprised a fivestep sequence as described in Fig. 3c. This chemistry was initially worked out using 21, and entailed, 1. acetylation of the C(15) alcohol; 2. deprotection of the TMSE ester, TFA group, and the C (17) and C(28) silyl ethers; 3 . esterification of the C(1) acid with tri-iso-propylsilyl chloride (TIPSCl); 4. double oxidation of the C (17) and C(28) alcohols; and 5. protection of the tertiary carbinol as its TES ether to produce the completed $\mathrm{ABCD}^{\star}$ fragment $\mathbf{6 a}$ in $50 \%$ yield over the five steps. Using this sequence starting from 25, we also synthesized two azide-bearing ester linker candidates at $\mathrm{C}(15), \mathbf{6 b}$ and $\mathbf{6 c}$. Overall, the route to $\mathrm{ABCD}^{*}$ fragments $\mathbf{6 a}-\mathbf{c}$ comprises just 18 steps in the longest linear sequence (LLS). The D-ring redesign had the intended impact on the ease and scalability of the synthesis of aldehydes $\mathbf{9}$, while the ease and scalability of the single step conversion of $\mathbf{1 2}$ and $\mathbf{9 b}$ to $\mathbf{2 5}$ made possible the rapid and far less resource- and time-intensive synthesis of the linker-bearing $\mathrm{ABCD}^{*}$ fragments.

Synthesis of the EF fragment. Our synthesis of the chlorodienebearing $\mathrm{EF}$ fragment commenced with a double cross-metathesis reaction between diene $\mathbf{2 6}$ and tert-butyl acrylate using the second-generation Hoveyda-Grubbs (HG-II) catalyst ${ }^{44}$ (Fig. 4). By using the acrylate as solvent we have been able to reduce the catalyst loading to an extraordinarily low level, with just $0.69 \mathrm{~mol}$ $\%$ catalyst resulting in isolation of $\mathbf{2 7}$ in $58 \%$ yield ${ }^{45}$. Double Sharpless asymmetric dihydroxylation $(\mathrm{AD})^{46}$ then delivered tetraol 28 in $65 \%$ yield as a $4.5: 1$ mixture of diastereomers ${ }^{47}$. Diastereoselective lactonization to establish the $\mathrm{C}(40)$ stereocenter was most effectively carried out using dry $\mathrm{HCl}$ in $\mathrm{MeOH}$ and was accompanied by transesterification to deliver lactone $\mathbf{2 9}$. Without isolation, this material was subjected to triple benzyl ether protection with 2,4,6-tris(benzyloxy)-1,3,5-triazene (Tri$\mathrm{BOT})^{48}$ giving lactone $\mathbf{3 0}$ as a single diastereomer (the minor meso diastereomer from the double $\mathrm{AD}$ reaction does not undergo the lactonization reaction) in $62 \%$ yield over two steps. Petasis methylenation ${ }^{49,50}$ of both carbonyls gave bis enol ether 31 in 55\% yield, both setting up a hydroboration/ $B$-alkyl Suzuki reaction for the allyl sidechain introduction and converting the methyl ester to a methyl ketone in masked form. Chemo- and diastereoselective hydroboration of $\mathbf{3 1}$ with 9-borabicyclo[3.3.1] nonane $(9-\mathrm{BBN})^{51}$ was followed by $B$-alkyl Suzuki coupling ${ }^{52}$ with vinyl bromide 32 and acidic hydrolysis of the methyl enol ether to deliver the fully elaborated F-ring methyl ketone $\mathbf{3 3}$ in $49 \%$ yield. Though we do not know the detailed mechanistic origin of the chemoselectivity of the hydroboration reaction for the cyclic enol ether, we note that attempts to accelerate the reaction by conducting it at higher temperatures led to competitive hydroboration of the acyclic methyl enol ether and lower overall yields of 33. Introduction of the E-ring commenced with a diastereoselective aldol reaction of methyl ketone $\mathbf{3 3}$ with aldehyde 34 to give 35 in $84 \%$ yield with 11:1 diastereoselectivity 31,33 Acid-promoted ketalization delivered $\mathbf{3 6}$ in $70 \%$ yield, and alcohol protection gave 37 in $87 \%$ yield. Four protecting group and functional group manipulations (1. reductive removal of all 5 benzyl groups ${ }^{25}$, 2. persilylation of all 5 alcohols, 3. selective deprotection of the two primary alcohols, and 4. chlorination of both primary alcohols) delivered allylchloride $\mathbf{1 3}$ in $55 \%$ yield
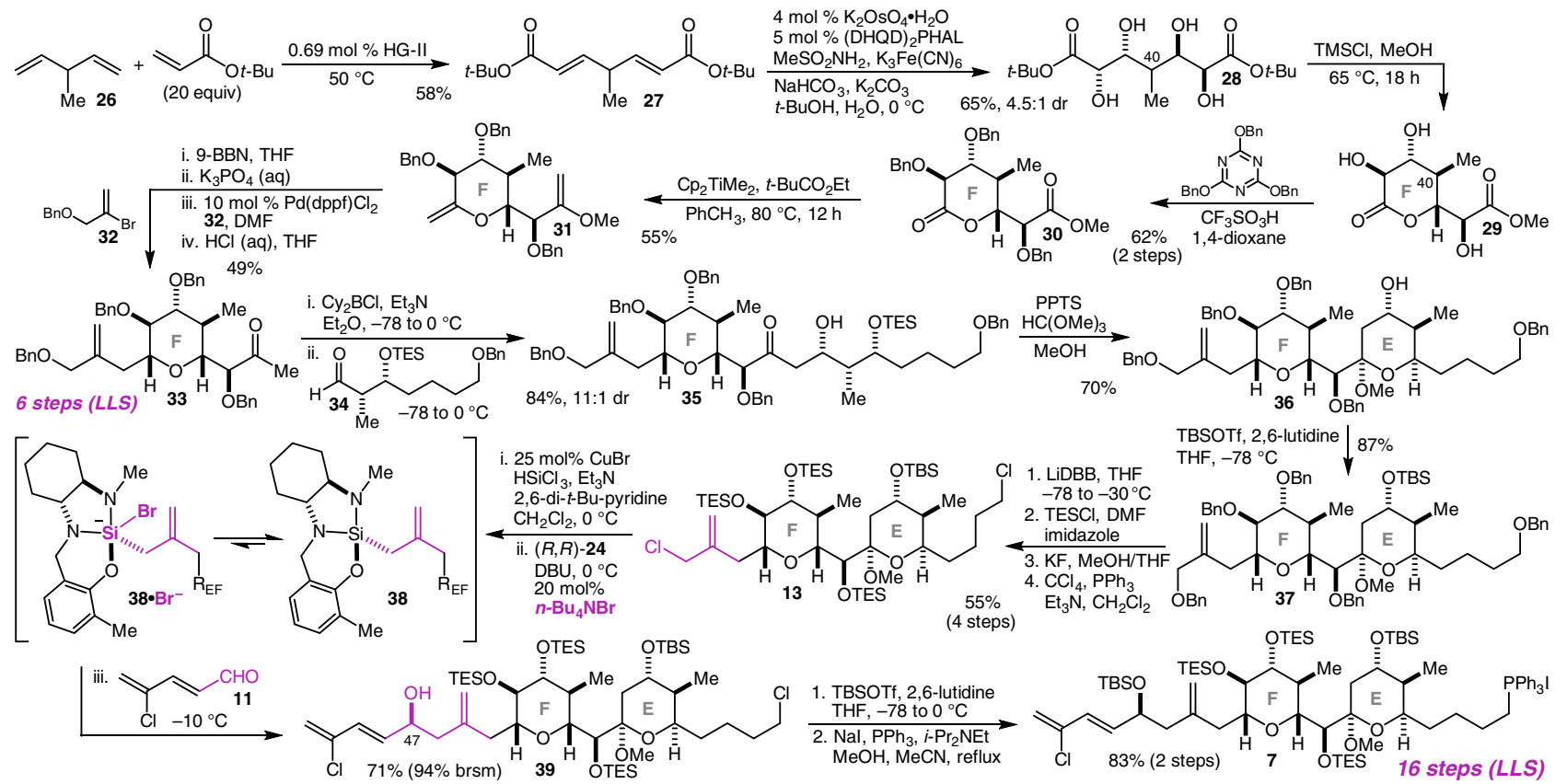

Fig. 4 A 16-step synthesis of the fully elaborated EF fragment of the spongistatins. Key steps include the double CM, double AD, and diastereoselective lactonization sequence that provides F-ring lactone $\mathbf{2 9}$ with five stereocenters in just three scalable steps, and the direct $n$-Bu ${ }_{4} \mathrm{NBr}$-catalyzed complex fragment coupling alkallylation reaction to incorporate the chlorodiene sidechain (13 $+\mathbf{1 1}$ to $\mathbf{3 9}$ ). (DHQD) 2 PHAL hydroquinidine 1,4-phthalazinediyl diether, TMSCI trimethylsilyl chloride, PPTS pyridinium para-toluenesulfonate, TBSOTf tert-butyldimethylsilyl triflate, LiDBB lithium 4,4'-di-tertbutylbiphenylide 
over four steps, setting up the critical complex fragment coupling alkallyation reaction. In analogy to the diene hydrosilylation/ diaminophenol complexation sequence described above, activated alkallylsilanes may be accessed from the corresponding alkallyl chlorides by way of the Benkeser-Furuya reaction ${ }^{53}$ and in situ diaminophenol complexation. Alkallysilanes derived from complex and sterically hindered alkallyl chlorides such as $\mathbf{1 3}$ react very slowly, however, and the attempted coupling of $\mathbf{3 8}$ (derived from 13 and diaminophenol 24) with aldehyde 11 led mainly to decomposition. This impasse inspired a search for ways to accelerate these reactions and this led to the discovery that weakly coordinating anions (e.g. $\mathrm{Br}^{-}, \mathrm{I}^{-}, \mathrm{TfO}^{-}$) are effective catalysts that operate, the evidence suggests, by adding to the allylsilane and accessing small equilibrium concentrations of the more highly activated allylsilicate ${ }^{54}$. When the coupling of $\mathbf{1 3}$ and $\mathbf{1 1}$ was repeated in the presence of $20 \mathrm{~mol} \% n-\mathrm{Bu}_{4} \mathrm{NBr}$, the desired product 39 was produced as a single diastereomer $(\geq 20: 1 \mathrm{dr})$ in $71 \%$ yield ( $94 \%$ based on recovered allylchloride 13 ), presumably through the intermediacy of the activated allylsilicate $38 \cdot \mathrm{Br}^{-}$. Alcohol protection was followed by a one-pot Finkelstein reaction and phosphonium salt formation ${ }^{23}$ to deliver the fully elaborated EF fragment 7 in $83 \%$ yield over two steps. Overall, this synthesis of the EF fragment comprises just 16 steps in the longest linear sequence. This step economy derives in large part from the development of a six-step synthesis of F-ring methyl ketone 33, and the direct fragment coupling alkallylation reaction to install the chlorodiene sidechain and C(47) stereocenter in a single step.

Completion of the synthesis and biological evaluation. Wittig coupling of EF fragment 7 with aldehydes $\mathbf{6 a - c}$ proceeded smoothly and delivered $40 \mathbf{a}-\mathbf{c}$, in $58-63 \%$ yields (Fig. 5a). Selective deprotection of the TIPS ester and the $C(41)$ and $C(42)$ TES groups was carried out with $n$ - $\mathrm{Bu}_{4} \mathrm{NF} \cdot 3 \mathrm{H}_{2} \mathrm{O}$ to give the hydroxy acids 41 a-c in $79-84 \%$ yields, which were subjected to macrolactonization employing the Yamaguchi protocol ${ }^{55}$ to give the macrolactones $\mathbf{4 2 a - c}$ in $77-87 \%$ yields. Global deprotection of the remaining silyl ether-protecting groups as well as E-ring ketal hydrolysis was effected with aqueous HF to deliver the target structures $\mathbf{5 a - c}$ in $82-83 \%$ yields. These compounds were evaluated for in vitro cytotoxicity against the 1A9 (A2780, ovarian), PC3 (prostate), Ca46 (lymphoma), and U937 (lymphoma) cell lines, using paclitaxel as a reference compound in the absence of a sample of spongistatin 1 (Fig. 5b; Supplementary Table 1). First and most critically, the data reveal that $\mathbf{5 a}$ is characterized by potencies in a similar range (i.e. low picomolar) to the parent natural product (Smith has reported a potency for spongistatin 1 of $0.059 \mathrm{nM}$ against the U937 cell line ${ }^{36}$ ), consistent with our hypothesis regarding the primary role of the $\mathrm{CD}$ spiroketal as structural/conformational scaffolding and validating the D-ring redesign. Second, the data show that whereas the benzoate derivative $\mathbf{5 b}$ is more than an order of magnitude less potent than $\mathbf{5 a}$, the aliphatic ester $\mathbf{5} \mathbf{c}$ is only slightly ( $\sim$ three-fold) less potent than 5a. While caution must be exercised when attempting to rationalize such small changes in potency, these data are consistent with the hypothesis that whereas the change from an acetate to a benzoate results in significant local conformational changes in the vicinity of $\mathrm{C}(15)$, the extension of an acetate to a higher order alkyl ester does not. While further optimization of the structure of the C(15)-azide-bearing acyl group to minimize any loss in potency may be desirable, these results constitute a proof-ofconcept that the $\mathrm{C}(15)$-acetate may be structurally modified without a significant loss of activity.

\section{Discussion}

Some $70 \%$ of all ADCs currently in clinical development use either a maytansinoid or an auristatin as the payload ${ }^{56}$, mainly because they are two of the only drugs that meet the criteria, including that they are readily available in significant quantity. Even within the microtubule-targeting drug class, it may be that that certain payloads perform more effectively against certain a

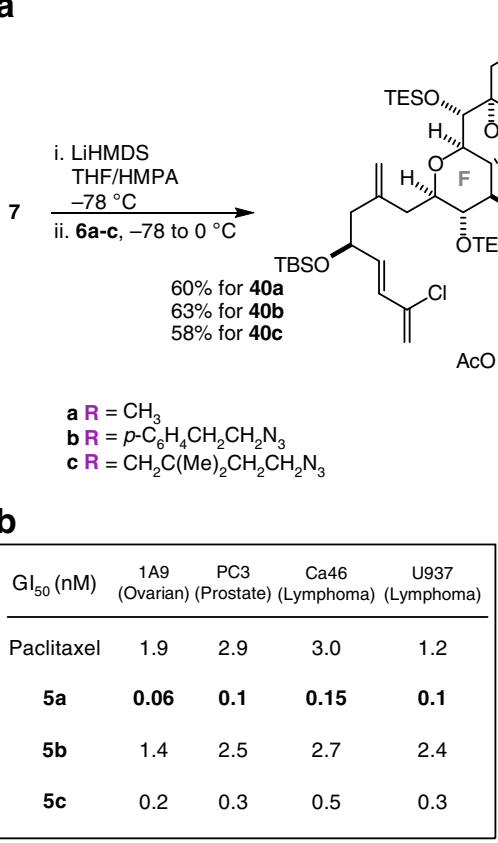

OTBS<smiles>CCCC1CCCCC1C</smiles><smiles>CCCCCC</smiles>
40 $\mathrm{CO}_{2}$ TIPS

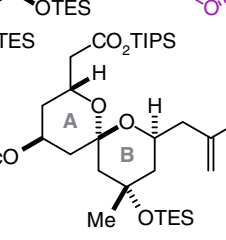<smiles>COC1CC2CCC2C2CC2C1</smiles><smiles>OC1COCO1</smiles>
H"'." Me<smiles>[M]C(C(C)C(C)C)C(C)C(C)CC</smiles><smiles>COC(C)=O</smiles><smiles>CO</smiles>
${ }^{\mathrm{R}}$
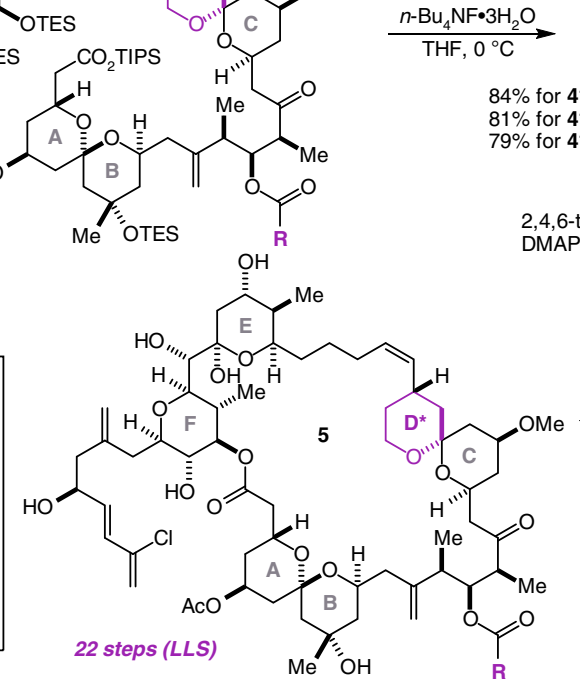

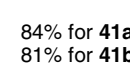
$79 \%$ for $41 \mathrm{c}$ TBSC

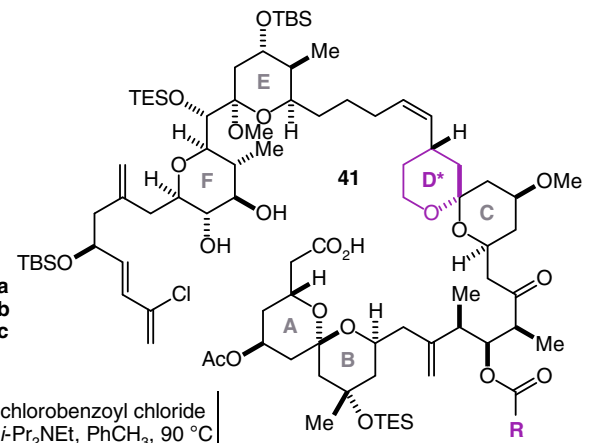
2,4,6-trichlorobenzoyl chloride
DMAP, $j-\mathrm{Pr}_{2} \mathrm{NEt}, \mathrm{PhCH}_{3}, 90^{\circ} \mathrm{C}$ $81 \%$ for $42 a$ $77 \%$ for $\mathbf{4 2 b}$ $87 \%$ for $42 \mathrm{c}$ TESO

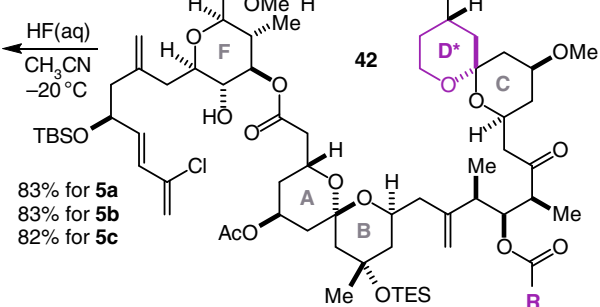

Fig. 5 Completion of the syntheses and cell growth inhibition data. a Four steps couple the ABCD* and EF fragments and produce the spongistatin 1 analogs $\mathbf{5 a - c . ~ b}$ Cell growth inhibition assays with four human cancer cell lines establish that the D-ring modified analog $\mathbf{5 a}$ is approximately equipotent with spongistatin 1, while $\mathbf{5 c}$ represents a proof-of-concept result that the $\mathrm{C}(15)$ acetate may be structurally modified with only a minimal reduction in potency. LiHMDS lithium hexamethyldisilazide, HMPA hexamethylphosphoramide 
cancers than others ${ }^{57}$, and an expanded pool of potential payloads for ADC development could advance the field in significant ways ${ }^{58}$. Many of these drugs are structurally complex natural products that are unavailable in quantity from natural sources and/or that do not have a synthetically selective and pharmacologically innocent linker functional group, however, and while ideally the limits of chemical synthesis would never prevent efforts to develop such compounds, the reality is that, especially with compounds as complex as the spongistatins, lengthy syntheses are often required that do not readily lend themselves to these kinds of drug development efforts. Indeed, the previous syntheses of spongistatin 1 and 2 have all required $\geq 30$ steps in the longest linear sequence and $\geq 105$ total steps. Due to the development of powerful and uniquely enabling new methodologies and strategies including the direct diaminophenol-activated complex fragment coupling crotylsilylation and $n-\mathrm{Bu}_{4} \mathrm{NBr}-$ catalyzed alkallylsilylation reactions, the synthesis described here proceeds in 22 steps in the longest linear sequence $(1.4 \%$ overall yield) and 68 total steps. This is important not only in advancing the frontiers of step economy and efficiency in the synthesis of non-aromatic polyketide natural products ${ }^{59-62}$, but also in facilitating the compound development efforts necessary to begin evaluating whether the spongistatins, properly configured for use in ADCs and other conjugates, can serve as effective payloads. In the present case, this step economy and efficiency have allowed us to validate the D-ring redesign and rendered the synthesis and evaluation of linker functional group-equipped analogs $5 b$ and $5 c$ a far less laborious and time- and resourceintensive effort and have allowed us to secure a crucial proof-ofconcept result in the form of $\mathbf{5 c}$, a highly potent linker-equipped analog of the spongistatins. Having validated the D-ring redesign and the $\mathrm{C}(15)$ acyl group linker strategy, our ongoing efforts are focused on a campaign to produce significant quantities of both 25 and 7 in order both to further optimize the structure of the $\mathrm{C}$ (15) acyl linker group for full potency retention and to use the optimized structure in the preparation and evaluation of conjugates.

\section{Methods}

General. All reactions were carried out under an atmosphere of nitrogen in flamedried glassware with magnetic stirring unless otherwise indicated. Degassed solvents were purified by passage through an activated alumina column. Thin-layer chromatography (TLC) was carried out on glass backed silica gel TLC plates (250 $\mu \mathrm{m})$ from Silicycle; visualization by UV light, cerium ammonium molybdate (CAM), phosphomolybdic acid (PMA), $p$-anisaldehyde stain, or potassium permanganate $(\mathrm{KMnO} 4)$ stain. HPLC analysis was carried out on an Agilent 1200 Series using a Chiralpak OD-H $(250 \times 4.5 \mathrm{~mm}$ ID) column. Diastereomeric ratios for all compounds were determined by ${ }^{1} \mathrm{H}$ NMR analysis of the unpurified reaction mixtures. ${ }^{1} \mathrm{H}$ NMR spectra were recorded on a Bruker AVIII $400(400 \mathrm{MHz})$ and AVIII $500(500 \mathrm{MHz})$ spectrometer and are reported in ppm, relative to residual protonated solvent peak $\left(\mathrm{CDCl}_{3}, 7.26 \mathrm{ppm}\right)$ unless otherwise indicated. Data are reported as follows: $\mathrm{bs}=$ broad singlet, $\mathrm{s}=$ singlet, $\mathrm{d}=$ doublet, $\mathrm{t}=$ triplet, $\mathrm{q}=$ quartet, $\mathrm{m}=$ multiplet, $\mathrm{dd}=$ doublet of doublets, $\mathrm{ddd}=$ doublet of doublet of doublets, $\mathrm{ddt}=$ doublet of doublet of triplets, $\mathrm{td}=$ triplet of doublets; coupling constant(s) in $\mathrm{Hz}$; integration). Proton decoupled ${ }^{13} \mathrm{C}$ NMR spectra were recorded on a Bruker AVIII $400(100 \mathrm{MHz})$ and AVIII $500(125 \mathrm{MHz})$ spectrometer and are reported in ppm from $\mathrm{CDCl}_{3}$ internal standard $(77.00 \mathrm{ppm})$ unless otherwise indicated. High-resolution mass spectra were obtained from the Columbia University Mass Spectrometry Facility on a Waters XEVO G2XS QToF mass spectrometer equipped with a UPC2 SFC inlet, electrospray ionization probe, and atmospheric pressure chemical ionization probe. Infrared spectra were recorded on a Perkin Elmer Paragon 1000 FT-IR spectrometer. Optical rotations were recorded on a Jasco DIP-1000 digital polarimeter. $\mathrm{pH} 7.00$ buffered silica gel was prepared as follows: A $1000 \mathrm{~mL}$ round bottom flask charged with silica gel $(250 \mathrm{~g})$ and $25.0 \mathrm{~mL}$ of $\mathrm{pH} 7.00$ buffer solution (potassium dihydrogen phosphate/sodium hydroxide; Fluka Analytical) was stirred on rotavapor under atmospheric pressure overnight.

\section{Data availability}

The authors declare that the data supporting the findings of this study are available within the paper and the Supplementary Information as well as from the authors upon reasonable request.
Received: 6 June 2018 Accepted: 24 October 2018

Published online: 09 November 2018

\section{References}

1. Pettit, G. R. et al. Antineoplastic agents. 257. Isolation and structure of spongistatin 1. J. Org. Chem. 58, 1302-1304 (1993).

2. Fusetani, N., Shinoda, K., Matsunaga, S. \& Cinachyrolide, A. A potent cytotoxic macrolide possessing two spiro ketals from marine sponge Cinachyra sp. J. Am. Chem. Soc. 115, 3977-3981 (1993).

3. Kobayashi, M. et al. Altohyrtin A, a potent anti-tumor macrolide from the Okinawan marine sponge Hyrtios altum. Tetrahedron Lett. 34, 2795-2798 (1993).

4. Bai, R., Cichacz, Z. A., Herald, C. L., Pettit, G. R. \& Hamel, E. Spongistatin 1, a highly cytotoxic, sponge-derived, marine natural product that inhibits mitosis, microtubule assembly, and the binding of Vinblastine to tubulin. Mol. Pharmacol. 44, 757-766 (1993).

5. Carter, P. J. \& Senter, P. D. Antibody-drug conjugates for cancer therapy. Cancer J. 14, 154-169 (2008).

6. Perez, H. L. et al. Antibody-drug conjugates: current status and future directions. Drug Discov. Today 19, 869-881 (2014).

7. Chari, R. V. J., Miller, M. L. \& Widdison, W. C. Antibody-drug conjugates: an emerging concept in cancer therapy. Angew. Chem. Int. Ed. 53, 3796-3827 (2014).

8. Polakis, P. Antibody drug conjugates for cancer therapy. Pharmacol. Rev. 68, 3-19 (2016)

9. Rothmeier, A. S. et al. The marine compound spongistatin 1 targets pancreatic tumor progression and metastasis. Int. J. Cancer 127, 1096-1105 (2010).

10. $\mathrm{Xu}, \mathrm{Q}$. et al. In vitro and in vivo anticancer activity of $(+)$-spongistatin 1 . Anticancer Res. 31, 2773-2779 (2011).

11. Chou, T.-C. et al. Therapeutic effect against human xenograft tumors in nude mice by the third generation microtubule stabilizing epothilones. Proc. Natl Acad. Sci. USA 105, 13157-13162 (2008).

12. Ho, S., Sackett, D. L. \& Leighton, J. L. A 'methyl extension' strategy for polyketide natural product linker site validation and its application to the microtubule-stabilizing agent Dictyostatin. J. Am. Chem. Soc. 137, 14047-14050 (2015)

13. Foley, C. N., Chen, L.-A., Sackett, D. L. \& Leighton, J. L. Synthesis and evaluation of a linkable functional group-equipped analog of the epothilones. ACS Med. Chem. Lett. 8, 701-704 (2017).

14. Boger, D. L. The difference a single atom can make: synthesis and design at the chemistry-biology interface. J. Org. Chem. 82, 11961-11980 (2017).

15. Roach, J. J. et al. Dynamic strategic bond analysis yields a ten-step synthesis of 20-nor-Salvinorin A, a potent k-OR agonist. ACS Cent. Sci. 3, 1329-1336 (2017).

16. Evans, D. A., Coleman, P. J. \& Dias, L. C. Enantioselective synthesis of altohyrtin $\mathrm{C}$ (spongistatin 2): synthesis of the $\mathrm{AB}$ - and $\mathrm{CD}$-spiroketal subunits. Angew. Chem. Int. Ed. 36, 2738-2741 (1997).

17. Evans, D. A., Trotter, B. W., Côté, B. \& Coleman, P. J. Enantioselective synthesis of altohyrtin C (spongistatin 2): synthesis of the EF-Bis(pyran) subunit. Angew. Chem. Int. Ed. 36, 2741-2744 (1997).

18. Evans, D. A. et al. Enantioselective synthesis of altohyrtin C (spongistatin 2): fragment assembly and revision of the spongistatin 2 stereochemical assignment. Angew. Chem. Int. Ed. 36, 2744-2747 (1997).

19. Evans, D. A. et al. Enantioselective total synthesis of altohyrtin C (spongistatin 2). Tetrahedron 55, 8671-8726 (1999).

20. Guo, J. et al. Total synthesis of altohyrtin A (spongistatin 1): Part 1. Angew Chem. Int. Ed. 37, 187-192 (1998).

21. Hayward, M. M. et al. Total synthesis of altohyrtin A (spongistatin 1): Part 2 Angew. Chem. Int. Ed. 37, 192-196 (1998).

22. Smith, A. B. et al. The spongistatins: architecturally complex natural products -Part One: A formal synthesis of $(+)$-spongistatin 1 by construction of an advanced ABCD fragment. Angew. Chem. Int. Ed. 40, 191-195 (2001).

23. Smith, A. B. et al. The spongistatins: architecturally complex natural products -Part Two: Synthesis of the C(29-51) subunit, fragment assembly, and final elaboration to (+)-Spongistatin 2. Angew. Chem. Int. Ed. 40, 196-199 (2001).

24. Smith, A. B. III et al. Spongipyran synthetic studies. Total synthesis of (+)-Spongistatin 2. Tetrahedron 65, 6470-6488 (2009).

25. Smith, A. B. III et al. Spongipyran synthetic studies. Evolution of a scalable total synthesis of (+)-spongistatin 1. Tetrahedron 65, 6489-6509 (2009).

26. Paterson, I. et al. Stereocontrolled total synthesis of $(+)$-altohyrtin A/ spongistatin 1. Angew. Chem. Int. Ed. 40, 4055-4060 (2001).

27. Paterson, I. et al. The stereocontrolled total synthesis of altohyrtin A/ spongistatin 1: the AB-spiroacetal segment. Org. Biomol. Chem. 3, 2399-2409 (2005). 
28. Paterson, I., Coster, M. J., Chen, D. Y.-K., Gibson, K. R. \& Wallace, D. J. The stereocontrolled total synthesis of altohyrtin A/spongistatin 1: the CDpiroacetal segment. Org. Biomol. Chem. 3, 2410-2419 (2005).

29. Paterson, I. et al. The stereocontrolled total synthesis of altohyrtin A/ spongistatin 1: the southern hemisphere EF segment. Org. Biomol. Chem. 3, 2420-2430 (2005).

30. Paterson, I. et al. The stereocontrolled total synthesis of altohyrtin A/ spongistatin 1: fragment couplings, completion of the synthesis, analogue generation and biological evaluation. Org. Biomol. Chem. 3, 2431-2440 (2005).

31. Crimmins, M. T., Katz, J. D., Washburn, D. G., Allwein, S. P. \& McAtee, L. F. Asymmetric total synthesis of spongistatins 1 and 2. J. Am. Chem. Soc. 124, 5661-5663 (2002).

32. Hubbs, J. L. \& Heathcock, C. H. A second-generation synthesis of the C1-C28 portion of the altohyrtins (spongistatins). J. Am. Chem. Soc. 125, 12836-12843 (2003).

33. Heathcock, C. H. et al. Multigram synthesis of the C29-C51 subunit and completion of the total synthesis of altohyrtin C (spongistatin 2). J. Am. Chem. Soc. 125, 12844-12849 (2003).

34. Ball, M. et al. Total synthesis of spongistatin 1: a synthetic strategy exploiting its latent pseudo-symmetry. Angew. Chem. Int. Ed. 44, 5433-5438 (2005).

35. Kraus, H. et al. Synthesis of spongistatin 2 employing a new route to the EF fragment. Chem. Sci. 4, 1989-1994 (2013).

36. Smith, A. B.III et al. Design, synthesis, and biological evaluation of diminutive forms of (+)-spongistatin 1: lessons learned. J. Am. Chem. Soc. 133, 14042-14053 (2011).

37. Kim, H., Ho, S. \& Leighton, J. L. A more comprehensive and highly practical solution to enantioselective aldehyde crotylation. J. Am. Chem. Soc. 133, 6517-6520 (2011).

38. Suen, L. M., Steigerwald, M. L. \& Leighton, J. L. A new and more powerfully activating diamine for practical and scalable enantioselective aldehyde crotylsilylation reactions. Chem. Sci. 4, 2413-2417 (2013).

39. Reznik, S. K. \& Leighton, J. L. Toward a more step-economical and scalable synthesis of spongistatin 1 to facilitate cancer drug development efforts. Chem. Sci. 4, 1497-1501 (2013).

40. Evans, D. A., Dart, M. J., Duffy, J. L. \& Yang, M. J. A stereochemical model for merged 1,2- and 1,3-asymmetric induction in diastereoselective mukaiyama aldol addition reactions and related processes. J. Am. Chem. Soc. 118, 4322-4343 (1996).

41. Tsuji, J., Hara, M. \& Ohno, K. Organic synthesis by means of noble metal complexes-XCIV: palladium catalyzed hydrosilylation of monoenes and conjugated dienes. Tetrahedron 30, 2143-2146 (1974).

42. Zhang, X., Houk, K. N. \& Leighton, J. L. Origins of stereoselectivity in strainrelease allylations. Angew. Chem. Int. Ed. 44, 938-941 (2005).

43. Evans, D. A., Dart, M. J., Duffy, J. L. \& Rieger, D. L. Double stereodifferentiating aldol reactions. The documentation of "partially matched" aldol bond constructions in the assemblage of polypropionate systems. J. Am. Chem. Soc. 117, 9073-9074 (1995).

44. Garber, S. B., Kingsbury, J. S., Gray, B. L. \& Hoveyda, A. H. Efficient and recyclable monomeric and dendritic Ru-based metathesis catalysts. J. Am. Chem. Soc. 122, 8168-8179 (2000).

45. Abbas, M. \& Slugovc, C. As low as reasonably achievable catalyst loadings in the cross metathesis of olefins with ethyl acrylate. Tetrahedron Lett. 52, 2560-2562 (2011).

46. Kolb, H. C., VanNieuwenhze, M. S. \& Sharpless, K. B. Catalytic asymmetric dihydroxylation. Chem. Rev. 94, 2483-2547 (1994).

47. Tanis, P. S., Infantine, J. R. \& Leighton, J. L. Exploiting pseudo C2_symmetry for an efficient synthesis of the F-ring of the spongistatins. Org. Lett. 15, 5464-5467 (2013).

48. Yamada, K., Fujita, H. \& Kunishima, M. A novel acid-catalyzed $O$-benzylating reagent with the smallest unit of imidate structure. Org. Lett. 14, 5026-5029 (2012).

49. Petasis, N. A. \& Bzowej, E. I. Titanium-mediated carbonyl olefinations. 1. Methylenations of carbonyl compounds with dimethyltitanocene. J. Am. Chem. Soc. 112, 6392-6394 (1990).

50. Payack, J. F. et al. Dimethyltitanocene: from millimole to kilomole. Org. Proc. Res. Dev. 8, 256-259 (2004).

51. Reddy, T. V. S.1-Methylene sugars as C-glycoside precursors. J. Org. Chem. 51, 5458-5461 (1986).

52. Chemler, S. R., Trauner, D. \& Danishefsky, S. J. The B-alkyl Suzuki-Miyaura cross-coupling reaction: development, mechanistic study, and applications in natural product synthesis. Angew. Chem. Int. Ed. 40, 4544-4568 (2001).

53. Furuya, N. \& Sukawa, T. The condensation reaction of trichlorosilane with allylic chlorides catalyzed by copper salts in the presence of a tertiary amine. J. Organomet. Chem. 96, C1-C3 (1975).
54. Tekle-Smith, M. A., Williamson, K. S., Hughes, I. F. \& Leighton, J. L. Direct, mild, and general $n$ - $\mathrm{Bu}_{4} \mathrm{NBr}$-catalyzed aldehyde allylsilylation with allyl chlorides. Org. Lett. 19, 6024-6027 (2017).

55. Inanaga, J., Hirata, K., Saeki, H., Katsuki, T. \& Yamaguchi, M. A rapid esterification by means of mixed anhydride and its application to large-ring lactonization. Bull. Chem. Soc. Jpn 52, 1989-1993 (1979).

56. Chari, R. V. J. Expanding the reach of antibody-drug conjugates. ACS Med. Chem. Lett. 7, 974-976 (2016).

57. Chen, H., Lin, Z., Arnst, K. E., Miller, D. D. \& Li, W. Tubulin inhibitor-based antibody-drug conjugates for cancer therapy. Molecules 22, 1281-1308 (2017).

58. Mantaj, J., Jackson, P. J. M., Rahman, K. M. \& Thurston, D. E. From anthramycin to pyrrolobenzodiazepine (PBD)-containing antibody-drug conjugates (ADCs). Angew. Chem. Int. Ed. 56, 462-488 (2017).

59. Ho, S., Bucher, C. \& Leighton, J. L. A highly step-economical snthesis of dictyostatin. Angew. Chem. Int. Ed. 52, 6757-6761 (2013).

60. Chen, L.-A., Ashley, M. A. \& Leighton, J. L. Evolution of an efficient and scalable nine step (longest linear sequence) synthesis of zincophorin methyl ester. J. Am. Chem. Soc. 139, 4568-4573 (2017).

61. Feng, J., Kasun, Z. A. \& Krische, M. J. Enantioselective alcohol C-H functionalization for polyketide construction: unlocking redox-economy and site-selectivity for ideal chemical synthesis. J. Am. Chem. Soc. 138, 5467-5478 (2016).

62. Wender, P. A. et al. Scalable synthesis of bryostatin 1 and analogs, adjuvant leads against latent HIV. Science 358, 218-223 (2017).

\section{Acknowledgements}

Financial support from the National Institute of General Medical Sciences (R01GM058133 to J.L.L., and postdoctoral fellowship (F32GM090487) to P.S.T.), the National Science Foundation (Graduate Research Fellowships to L.M.S. and M.A.T.-S.), the American Cancer Society (postdoctoral fellowship (124489-PF-13-311-01-CDD) to K.S.W.), and the Intramural Research Program of the Eunice Kennedy Shriver National Institute of Child Health and Human Development, National Institutes of Health is gratefully acknowledged.

\section{Author contributions}

J.L.L. designed and directed the research project and wrote the manuscript. D.L.S. performed the assays described in Fig. 5b and Supplementary Table 1, and made contributions to the project design. Building on critical foundational work by S.K.R. and P.S. T., L.M.S., M.A.T.-S., K.S.W., and J.R.I. all made major contributions to the work reported here. T.D.C. made contributions to the synthesis of $9 \mathrm{~b}$ described in Fig. $3 \mathrm{a}$ and Supplementary Fig. 1.

\section{Additional information}

Supplementary Information accompanies this paper at https://doi.org/10.1038/s41467 018-07259-x.

Competing interests: The authors declare no competing interests.

Reprints and permission information is available online at http://npg.nature.com/ reprintsandpermissions/

Publisher's note: Springer Nature remains neutral with regard to jurisdictional claims in published maps and institutional affiliations.

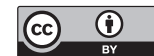

Open Access This article is licensed under a Creative Commons Attribution 4.0 International License, which permits use, sharing, adaptation, distribution and reproduction in any medium or format, as long as you give appropriate credit to the original author(s) and the source, provide a link to the Creative Commons license, and indicate if changes were made. The images or other third party material in this article are included in the article's Creative Commons license, unless indicated otherwise in a credit line to the material. If material is not included in the article's Creative Commons license and your intended use is not permitted by statutory regulation or exceeds the permitted use, you will need to obtain permission directly from the copyright holder. To view a copy of this license, visit http://creativecommons.org/ licenses/by/4.0\%

(c) The Author(s) 2018 